\title{
Chinese Motion-Directional Construction: A Conceptual and Cognitive Analysis
}

\author{
Ronald Fong \\ University of Macau
}

\begin{abstract}
This article proposes an analysis of the Motion-Directional Construction in Chinese in the Conceptual-Cognitive approach as outlined by Jackendoff and Langacker. This article first argues that the Motion-Directional Construction consists of conceptual subordination, expressing different mental spaces. Then, it examines the syntactic and semantic behaviors of the construction arguing that it is more like a constructional idiom. In particular, we discuss the case of $p a$ 'climb' and generalize further that the motion verbs in Chinese typically express manners of movement. Within the Conceptual Semantics, we argue that a level of grammatical relation may not be necessary; it is the argument and conceptual structures that we need in the cognitive structure. Finally, we present the data and suggest the typological relevance of the Motion-Directional Construction.
\end{abstract}

\section{Keywords}

subordination, directional, Parallel Architecture, construction, conceptual structure

Studies in Chinese Linguistics, Volume 38, Number 2, 2017, 119-147 DOI: 10.1515/scl-2017-0006 (C)2017 by T.T. Ng Chinese Language Research Centre, Institute of Chinese Studies, The Chinese University of Hong Kong 


\section{Introduction}

While most linguists (e.g., Chao 1968; Huang et al. 2009; Li 1989; Li and Thompson 1981; Loar 2011) treat the Motion-Directional Construction (MDC) as a V-V compound, this article proposes that the construction is viewed as a construction of conceptual subordination (Goldberg 1995, Goldberg 2006; Langacker 2008, Langacker 2013). Furthermore, this article argues that the Motion-Directional Construction is better analyzed in the Parallel Architecture (PA), as outlined in Jackendoff (2002, 2007, 2010), Culicover (2013), and Culicover and Jackendoff (2005).

In Fong (2015), it is argued that the MDC in Chinese consists of syntactic and semantic subordination, and this article provides further conceptual support and evidence for the position. For example, pao jin fangzi 'run enter house' (ran into the house) contains the motion verb pao and the path verb jin. The temporal iconicity principle suggests that pao is prior to jin. Syntactically, the negative scope falls on jin rather than pao, as in pao bu jin fangzi 'run not enter house' (could not enter the house). Section 2 will provide more discussion of this position.

This article extends the analysis of the MDC in Chinese by Fong (2015) and will first argue for a conceptual interpretation of subordination, based upon cognitive-typological findings such as Cristofaro (2003, 2014) and Langacker (2014) before proposing that the MDC in Chinese is a variant of cognitive subordination, realized syntactically and semantically. Then, we will examine the foundations of the PA and its merits in the description of the MDC in Chinese. The syntactic and semantic characteristics of the MDC will be discussed before we examine the interaction between the grammatical function tier and the MDC we argue that this tier may not be necessary as a universal level in grammar. The interaction between arguments and the conceptual structure is discussed in more detail. Finally, we will make some observations about how the MDC fits in a model assuming Universal Grammar in evolutionary terms.

\section{Subordination}

First of all, we will need to define the kind of subordination that we are discussing. Apart from clausal subordination, subordination itself can be seen in a construction smaller than a clause, for instance, a compound. An example from English is coffee table. A coffee table is a kind of table, and thus coffee is subordinate to table, which is superordinate to coffee. Or the verb stir-fry indicates some kind of frying. Stirring is the manner in which frying is done. In the spirit of Cognitive Grammar (Langacker 2008, Langacker 2013), the two examples profile car and fry, which are the profile determinants, and the two examples show endocentricity. Endocentricity is not the single criterion that determines the status of a compound. The English example overhead projector has over and head, and neither of them can be head in this compound. 
At the clause level, subordination can be indicated by different properties, one of which is through the use of subordinators or complementizers.

(1) Although John said that he wanted to have fish for dinner, he would only have pork.

The words although and that are the subordinators, which signal the subordinate status of the clauses they introduce - both are subordinate to the main clause. One clause functions as a complement and the other functions as an adverbial. Thus, the subordinate clauses are syntactic constituents embedded in the main clause. This fairly traditional analysis captures the basic intuition of the structure of the sentence in that a clause contains a clause that contains another clause. Containment is one of the properties for subordination in Langacker's (2014) model, which argues differently from his previous viewpoint on subordination, which is the one that a subordinate clause is "describable as one whose profile is overridden by that of a main clause" (Langacker 1991: 436). In his later model, Langacker (2014) considers containment to be "conceptual rather than grammatical, consisting in the successive embedding of mental spaces" (Langacker 2014: 24). It is this conceptual interpretation of subordination that we apply to the MDC in Chinese. For a detailed analysis of the MDC as a syntactic subordination and arguments against it as a compound, see Fong (2015).

Another aspect of this interpretation involves the access to mental spaces, which operate in our working memory and can be "entrenched in long-term memory" (Fauconnier and Turner 2002: 103). Mental spaces are constructed when we talk or think or when "discourse unfolds" and they are "connected to each other by various kinds of mappings". Knowledge can be formed from "separate domains", which can build up a single mental space (Fauconnier 2007: 352). The notion of mental space is similar to that of domain in Cognitive Grammar, but "mental space emphasizes conceptual discontinuities, the partitioning of conceptual structure into semiautonomous regions" (Langacker 2008: 51). It further emphasizes the dynamic structure created in discourse. Thus, the theory offers a way of viewing the MDC in Chinese.

The MDC in Chinese under our analysis establishes mental spaces and in the construction "[e]ach matrix verb is a space builder, introducing a space that hosts the proposition..." (Langacker 2014: 24). A space builder is "a grammatical expression that either opens a new space or shifts focus to an existing space" (Fauconnier 1997: 40). I propose a slight change of this view of a space builder appropriate for a language such as Chinese, in which finiteness does not figure at the clause level - that is, each verb in the MDC is a space builder.

$\begin{array}{llll}\text { John } & \text { pao jin lai le. } \\ \text { John } & \text { run enter come CRS }\end{array}$

'John came in by running.'

(CRS $=$ Current Relevant State, Li and Thompson 1981) 
Example (2) consists of three verbs pao, jin and lai, which can occur as independent verbs in a clause.

(3) John pao le.

John run CRS

'John has run.'

(4) John jin wuzi le.

John enter house CRS

'John has entered the house.'

(5) John lai le.

John come CRS

'John has come.'

From (3-5), we can see that each verb activates a mental space in its own proposition expressed by the clause in which the verb occurs - running, entering and coming, as shown in Figure 1.

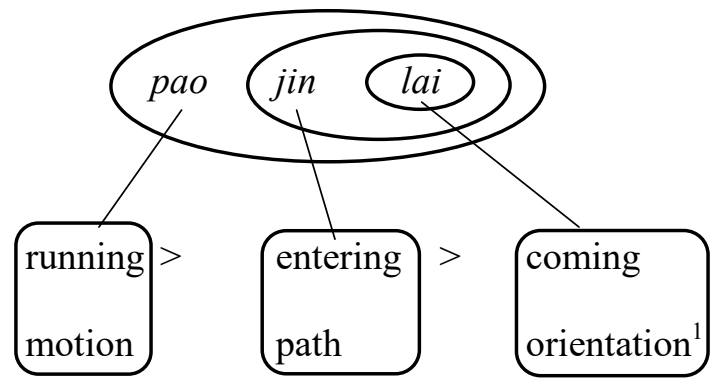

Figure 1 Mental spaces

I group the path and orientation verbs as directional verbs. They are organized into the following two types. Li and Thompson (1981: 58-59) group these two types together to form a third type such as jin lai 'enter', which is deemed unnecessary in this paper. The list of (i) contains the path verbs and that of (ii) orientation verbs.

(i) shang 'ascend', xia 'descend', jin 'enter', chu 'exit', $q i$ 'rise', hui 'return', guo 'cross' and kai 'open'

(ii) lai 'come' and $q u$ 'go'

When these verbs are used independently, they show physical motion and they are not subordinate to one another. However, when they occur together as in (2), the entire construction (MDC) aligns the second verb to the path and the third

1 I originally used the term deixis in the same sense of Levinson (2003: 69): "Deixis concerns the relativization of reference to properties of the speech event". A reviewer suggests that I use orientation instead, and I follow his/her advice. 
to orientation, which show conceptual subordination to the first motion verb. The MDC in Chinese employs the motion verb, which is typically monovalent or intransitive in the traditional sense, as in (3), as it does not allow a noun phrase complement or object, as in (6).

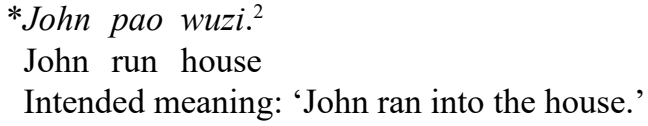

Apart from our earlier conceptual definition of a subordinate clause, which is "describable as one whose profile is overridden by that of a main clause", there are morpho-syntactic properties that suggests that the motion verb is the main verb, as argued in Fong (2015) and Talmy (2016). One of such properties is that the aspectual marker le can be attached to the motion verb as in John pao le jin qu 'John run ASP enter go' ('John ran inside'). Since Chinese does not mark tense but aspect, it can be assumed that the verb that shows aspectual meaning is the main verb. The reason why (6) is unacceptable lies in the fact that pao 'run' can be considered as a traditional intransitive or monovalent verb, which typically takes one Theme argument (and does not license a complement or object). This inability to take a complement does not disprove the assumption that the motion verb is the main verb because a main verb can be monovalent (intransitive) or bivalent (transitive).

Crosslinguistically, in English there are relevant counterparts such as *John ran the house and John ran into the house. The fact that the verb run does not license a noun phrase complement, but requires a prepositional phrase complement instead does not show that run is not the main verb, but it only shows it is intransitive in the traditional sense. The Chinese pao 'run' requires the path and orientation verbs because they are its complements, which are typically required by the head, which in this case is the motion verb. Since it is the head, the motion verb is arguably the main verb.

The same can be said to the English counterpart. The verb run, being the head of the verb phrase, requires a prepositional phrase as its complement. A complement, typically obligatory, is traditionally assumed to be subordinate to the head. Further, the head selects a particular kind of complement. The Chinese motion verb selects the path verb first and then the orientation verb, and not the other way around, similar to the English verb run, selecting a prepositional phrase headed by into but not other phrases. A further piece of evidence that supports our assumption that the motion verb is the main verb is that there is a cause and effect relation between the motion verb and the path and orientation verbs. The motion verb can be construed to be the cause, as, for instance, running is the cause of entering a building. (More arguments for the motion verb as the main verb in

2 I thank the reviewer for urging me to clarify the assumption of the motion verb as the main verb. A detailed analysis was proposed by Fong (2015). Talmy (2016) also makes a similar proposal. 
Chinese can be found in Fong 2015 and Talmy 2016.)

In addition to the above discussion of our assumption that the motion verb is the main verb of the predicate, this article makes use of the conceptual understanding of subordination. One of the advantages of this conceptual approach to subordination is that the morpho-syntactic properties alone may not be entirely responsible for recognizing the phenomenon. Another merit of this approach is that it is comparable to the PA (Figure 2) in that the conceptual or semantic structure, being an independent generative component, can be associated with phonology without the interference of syntax, when sometimes syntax may be meaningless. In a clause containing the MDC, the sentence-final particle le referring to "current relevance state" ( $\mathrm{Li}$ and Thompson 1981) is frequently used and it is employed more pragmatically than syntactically.

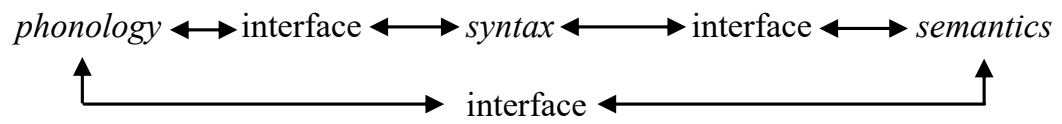

Figure 2 A simplified diagram of Jackendoff (2002: 125, 2007: 49, 2010: 3)

For instance, the verb pao has the following lexical conceptual structure:

(7) Phonology: /pav/

Syntax: V

Semantics: $\left[_{\text {Event }} \mathrm{GO}\left(\left[_{\text {Thing }} x\right]\right)\right]$

While the verb pao has all three components, le does not, as in (2) John pao jin lai le.

(8) Phonology: /la/

Syntax:

Semantics: [CRS $\left(\left[\left[_{\text {Proposition }} x\right]\right)\right.$

The semantic value is to be understood broadly to include pragmatics or world encyclopedia knowledge. The PA allows us to capture the differences of the two lexical items straightforwardly.

\section{The Parallel Architecture and the Motion-Directional Construction}

Culicover and Jackendoff (2005) reinforce the PA model by postulating the Simpler Syntax Hypothesis (Culicover 2015: 3, Culicover 2013: 2): "Syntactic structure is only as complex as it needs to be to establish interpretation". I see no contradiction between the Hypothesis and the Construction Grammar and Cognitive Grammar's commitments. The constructional approach is a what-yousee-is-what-you-get approach that shows surface syntax and no derivation or movement is employed. While Cognitive Grammar is sometimes criticized for the lack of formalization (Jackendoff 2007: 194), the overall architecture of the framework is highly compatible with the PA, as far as I can see. 
In Figure 2, there are three components, namely, phonology, syntax and semantics, connected with interface rules. A clause in the PA is well-formed when the three components are well-formed, and yet they are independent to some extent. A generative semantic or conceptual component assumes some basic conceptual primitives that human languages possess to describe the experience of human beings. These experiences include things like motion, causation, etc. Thus, in this model, the speakers of Chinese must have an abstract schema in the MDC that allows up to three verbs excluding one aspectual marker.

(9) John zou chu lai le.

John walk exit come CRS

'John came out by walking.'

(10) John pao jin qu le.

John run enter go CRS

'John entered by running.'

(11) John pao shang lai le.

John run rise come CRS

'John came up by running.'

All the three verbs in the MDC require a Theme, that is, John. These arrangements of the verbs follow the general temporal principle in Chinese. ${ }^{3}$

Revising Huddleston and Pullum (2002), Fong (2015) proposes a "Catenative Analysis" (Figure 3) of the MDC in Chinese, which analyzes the motion verb of the MDC as head and it licenses a subordinate clause or a non-finite VP as its complement that indicates the path. This is similar to the Simpler Syntax model that allows non-finite VPs without a syntactic subject, and the elliptical subject is identified by interface rules (Jackendoff 2010: 26). Thus, in Figure 3, the verbs pao and $j i n$ are predicated of the same individual.

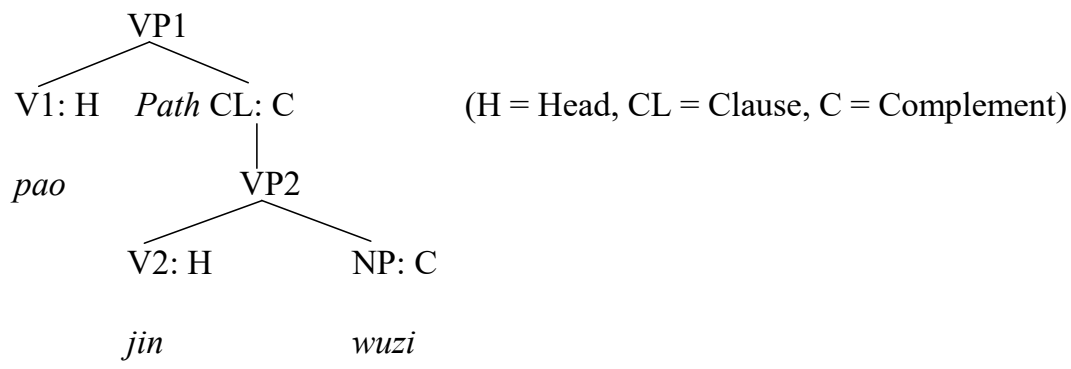

Figure 3 A phrase-marker of Catenative Analysis (Fong 2015)

3 Studies in Cantonese directional verbs include Cheung (2007) and Yiu (2005, 2013). Yiu (2005: 46), for example, classifies two types of directional verbs based upon their orientation points, with lai 'come' and $q u$ 'go' oriented towards the speaker as one type and with seong 'move up', lok 'move down' and so on oriented towards a physical location. 
This analysis also reflects the central idea of Merge in Minimalism that Merge is "a grouping operation which combines at least two elements forming a labeled set” (Boeckx 2006: 77-78).

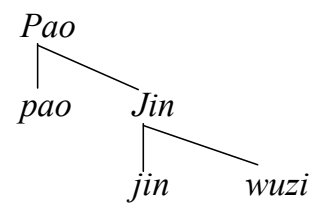

Figure 4 A phrase-marker of Minimalism

Figure 4 shows the Merge operation indicating the combinatoriality of linguistic structure. The PA extends this further to incorporate the operation unification: "unifying $\mathrm{A}$ and $\mathrm{B}$ results in a composite that shares all [the] common features of A and B and preserves all [the] distinct features of A and B" (Jackendoff 2007: 63). Thus, the example pao jin will have both properties of pao and those of jin. Keeping in line with Culicover and Jackendoff (2005: 41), more primitive "protolinguistic" principle of "parataxis (jamming constituents together in some linear order" and also with the PA objective that a simpler structure is preferred, the MDC will have the flat structure as Figure 5:

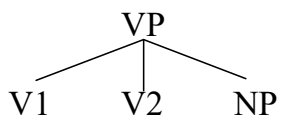

Figure 5 The schema of MDC

Binary branching, Culicover and Jackendoff (2005) argue, is not always an advantage, particularly when it comes to child language acquisition.

Figure 6 shows that the MDC allows one further slot for the verbs lai 'come' and $q u$ 'go'.

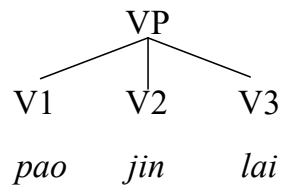

Figure 6 The schema of MDC with pao jin lai

With the three verbs, the construction further allows variation with the NP argument intervening V2 and V3. This is indicated in Figure 7. 


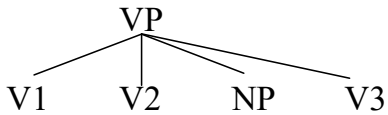

pao jin fangzi lai

Figure 7 The schema of MDC with pao jin fangzi lai

V3 designates orientation, as lai coming towards the speaker and qu moving away from the speaker. The syntactic behaviour of these two verbs can be expressed as a constraint - final position constraint. With or without the NP, these two verbs occur in the final position of the VP in the MDC.

With up to three verbs in the MDC, the grammatical relations among the verbs cannot "be inferred from the syntactic roles alone" (Croft 2001: 221). As indicated by Figure 8, with no obvious grammatical markers, V1 can be related to $\mathrm{V} 2$ or $\mathrm{V} 3, \mathrm{~V} 2$ to $\mathrm{V} 1$ or $\mathrm{V} 2$, and $\mathrm{V} 3$ to $\mathrm{V} 1$ or $\mathrm{V} 2$.

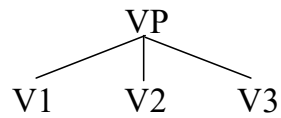

Figure $8 \mathrm{MDC}$ with three verbs

This variation parallels the verb-particle construction in English such as look a word up (cf. Jackendoff 2010: Ch. 7). Yet, V3 is not merely a particle but a full verb indirectly licensed by jin in the MDC, as the composition of jin lai is possible. Different from particles, the directional verbs in Chinese can have the following form of function-argument structure (adapted from Jackendoff 2010: 10):

$$
\left.\mathrm{PATH} \rightarrow{ }_{\text {Path }} \text { JIN/LAI } \quad \text { (PLACE) }\right]
$$

Furthermore, the directional verbs can occur as motion verbs in the V1 position as in John jin lai le 'John has come'. In this case, jin can indicate an event, and hence, has the following function-argument structure.

$$
\text { EVENT } \rightarrow \quad\{\text { Event } \text { JIN } \quad[(\text { THING, PATH })]\}
$$

This use of directional verbs has led to some linguists' arguments that Chinese is an "equipollent" language on a par with "satellite-framed" and "verb-framed" (e.g., Slobin 2004). For a different view, see Fong (2016).

Semantically, the MDC has the motion verb as its "profile equivalent that is the primary information-bearing unit" (Croft 2001: 259), and this echoes Langacker's conceptual understanding of subordination that the path verb and deictic verb are conceptually subordinate to the motion verb in the entire MDC. Speakers of Chinese must have a mental representation or schema for the MDC, similar to "[the] rules of grammar [that] are taken to be pieces of structure stored in memory" (Culicover 2013: 8). 


\subsection{The MDC as a constructional idiom}

The schematic pattern of MDC allows us to consider it as a construction similar to a constructional idiom - "pieces of syntactic structure that bear inherent meaning" (Jackendoff 2002: 392), and "is treated by the grammar like a special kind of phrasal lexical item, whose meaning is learnable in the same way word meanings are learned" (Jackendoff 2010: 273). Thus, the construction is viewed like a lexical item - symbolic in nature. On the one hand, the meaning of the MDC is compositional, showing the motion, direction and orientation; on the other hand, the metaphorical meaning occurs with certain combinations of the verbs.

(14) John he Mary pao qi lai.

John and Mary run rise come

'John and Mary started to run.'

The verbs qi lai can be interpreted as rise and in this case, it can be associated with the inchoative aspect. Likewise, the item xia qu meaning going down can indicate the progressive aspectual meaning.

(15) Women yao nuli xia qu.

We need effort descend go

'We need to keep working.'

The idiomatic nature of the MDC also comes from the position of the second NP argument (landmark), Figure 7 shows, repeated here as Figure 9. The argument fangzi 'house' occurs between the path verb and the deictic verb idiomatically.

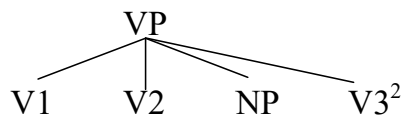

pao jin fangzi lai

Figure 9 The schema of MDC with pao jin fangzi lai

Furthermore, V3 must be filled by either lai 'come' or qu 'go', without too much variability. It seems that the speakers of Chinese must store them as "lexical VP idioms" in their long-term memory. The landmark argument is thus licensed by the entire construction, but it is not an argument of the motion verb pao 'run'. The variability of the lexical items in the MDC decreases from the motion verb to deictic verb.

4 A reviewer points out that the position of $\mathrm{V} 3$ can be occupied by $l i$ 裡 or wai 外. In this case, I will treat them not as V3 but a preposition or an adverb. 


\begin{tabular}{lcc} 
pao, zou, zuo, pa... & jin, chu, kai, guo & lai, qu \\
(open-ended) & hui, qi, shang, xia & \\
\hline
\end{tabular}

Figure 10 A continuum of the variability of lexical items in the MDC

Figure 10 shows that the members of the motion verb are open-ended, while there are eight directional verbs and two deictic verbs in the MDC, which shows a gradient of variability and complexity. This construction is so entrenched that it seems to have been constructionalized or grammaticalized - "a new construction is created along with a new grammatical morpheme; the latter evolves from a lexical morpheme or combinations of grammatical and lexical morphemes" (Bybee 2013: 530). With the MDC being constructionalized by the "micro-constructions" (Traugott and Trousdale 2013) or "mini-constructions" (Boas 2003) instantiated by the motion and directional verbs, respectively, this appears to be an accurate statement of the MDC in Chinese. ${ }^{5}$

\subsection{The case of $\mathrm{Pa}$ 'climb'}

Levin and Rappaport Hovav (2013) examines the syntactic behavior and the semantics of the verb climb in English closely. The verb $p a$ 'climb' in the MDC in Chinese seems to lexicalize upward direction as its counterpart in English usually does, as observed by Levin and Rappaport Hovav (2013: 59 (19a)).

(16) The trained climb.

(17) Zuo zhe huoche pa Taishan

sit ASP train climb Taishan $(\mathrm{ASP}=$ Aspect)

'I was climbing Taishan on a train.'

(http://www.mafengwo.cn/i/5351001.html)

Based upon Geuder and Weisgerber (2008), Levin and Rappaport Hovav later concur that the verb climb can indicate a downward movement as long as the motion "resists the pull of gravity" (2013: 60). Then, Levin and Rappaport Hovav (2013: 50) propose a hypothesis about motion verbs.

Manner/result complementarity: Manner and result meaning components are in complementary distribution: a verb lexicalizes only one.

The MDC in Chinese shows a strong tendency towards this hypothesis. In the

5 If we take jin as an example, we find that in Liji [Book of rites] many instances of jin are used without a complement as in 《禮記・曲禮》遭先生于道, 趨而進。(Liji:Quli [Book of rites: Summary of the rules of propriety]: Zao xiansheng yu dao, qu er jin). Yet, jin in modern Chinese is frequently used with a complement. 
sentence John pao jin lai, the verb pao indicates the manner, jin and lai indicate the result.

(18) *John pao jin le wuzi dan meiyou jin lai. John run enter CRS house but not enter come '*John ran into the house, but he did not get in.'

The verb $p a$ in Chinese can be concatenated with other verbs easily to show the path of the movement or orientation, partly because the verb $p a$ and other verbs can occur independently in a clause.

(19) John pa xia lai le.

John climb descend come CRS

'John came down by climbing.'

(20) John pa jin fangjian.

John climb enter room

'John entered the room by climbing.'

The Chinese $p a$ does not lexicalize an upward movement but only indicates the manner in which the motion is done. We can possibly generalize further and suggest that all motion verbs in the Chinese lexicon behave in the same way in the MDC, conforming to the manner/result complementarity principle.

However, in the case of single directional verbs indicating motion, we find that the situation is not that straightforward. As we will argue in Section 5, a directional verb such as jin, when occurring independently in a clause, seems to possess more than one meaning components. If we modify (20) and use only the directional verb $j i n$, as in John jin fangjian, it is not easy to tell whether jin lexicalizes only manner or result. It seems to lexicalize both aspects of meaning in the conceptual structure. One thing can be more certain, that is, the motion verb only indicates motion of different kinds. Section 5 will discuss this in further detail.

\section{Grammatical relations and conceptual structure}

Another consequence of our analysis of MDC in the PA is the allowance of the tier or level of the grammatical relations or functions. This level is not entirely obligatory and is not an intrinsic component in the model, but can be implemented, if necessary. For how major theories employ and interpret grammatical relations, see Farrell (2005). Figure 8 illustrates how the PA can make use of grammatical function tier. In Jackendoff's model (2002: 149-151), the grammatical relations largely refer to the syntactic relations such as subject and object rather than semantic roles. Similar to Jackendoff's model, Croft's Radical Construction Grammar $(2001,2012)$ dispenses with the global syntactic relations, which apply to various languages. This article sides with Jackendoff and Croft arguing that grammatical relations do not play a significant role in Chinese as many descriptions of Chinese grammar do (e.g., Huang et al. 2009; Li and Thompson 1981; Loar 
2011). Furthermore, I concur with LaPolla (1993) that the grammatical relations such as Subject and Object as construed in the Western linguistic literature does not really apply to Chinese.

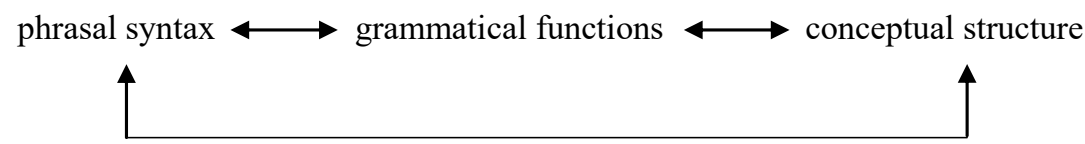

Figure 11 Grammatical function tier (adapted from Jackendoff 2002: 151)

This grammatical function tier, as in Figure 11, is formally developed further in Culicover and Jackendoff (2005), which is motivated by concerns such as raising and passive structures. However, a simple sentence such as John opened the door has the following conceptual structure and grammatical function (Culicover and Jackendoff 2005: 192).

$$
\begin{aligned}
& {\left[\mathrm{CAUSE}\left(\mathrm{JOHN}_{1},\left[\mathrm{BECOME}\left(\mathrm{DOOR}_{2}, \mathrm{OPEN}\right)\right]\right]_{3}\right.} \\
& \text { (agent) } \\
& \text { [ Clause } \left.\quad \mathrm{GF}_{1}>\mathrm{GF}_{2}\right]_{3}
\end{aligned}
$$

The Chinese equivalent John da kai men should have the same conceptual structure but can dispense with the grammatical function.

$$
\underset{(\text { agent })}{\left[\mathrm{DA}\left(\mathrm{JOHN}_{1},\left[\mathrm{BECOME}\left(\mathrm{MEN}_{2}, \mathrm{KAI}\right)\right]\right)\right]_{3}}
$$

This echoes Figure 1 that phrasal syntax is associated with conceptual structure without meddling with the grammatical function tier. Speakers of Chinese presumably follows the "Agent First" principle ${ }^{6}$ and assign John the agent role and men the theme role. Dispensing with the grammatical function tier in the description of Chinese has further consequences for the analysis of other constructions. Take the MDC for example.

(23) John pao jin wuzi le.

Wuzi John pao jin le.

house John run enter CRS

'House, John entered.'

The goal argument appears at the beginning of the sentence before the agent, and yet the agent occurs right before the verb. Thus, accommodating this fact in Chinese, the "Agent First" principle should be interpreted as the one that assigns the agent to the position preceding the (main) verb first - perhaps renamed as

\footnotetext{
6 Jackendoff's (2002: 248) Agent First Principle is meant to be a generalization, and other thematic roles can of course occupy the subject position in English or Chinese.
} 
the "First Agent Frist" principle. We first assign the agent role to an NP position before the verb and then assign other roles to other arguments. The second role assigned to the next argument is obviously the patient or goal.

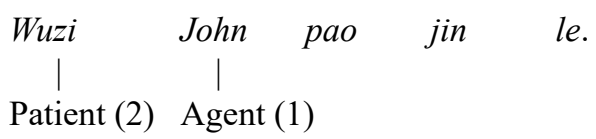

Jackendoff (2002: 150) says that "[t]he semantic roles appearing in this position [initial position of the clause] do not show an overwhelming commonality; they are certainly random in terms of thematic roles", and calls this position "syntactic topic". This is a welcome suggestion in our description of the MDC in Chinese, without employing an unnecessarily rigid grammatical function tier, which is what Jackendoff (2010: 27) calls "extra mechanism". Psychologically, if there is a grammatical function tier, this will delay the formation of the MDC in the above example, in terms of processing. The conceptual structure of this sentence is not much different from that of John pao jin wuzi le. Following the Simpler Syntax thesis and attempting to cover universals, we will be better off doing away with the grammatical function tier, particularly in the description of a language like Chinese.

On the other hand, rather than assuming the rigid phrase structure such as the X-bar model, Langacker (2013: 212) recognizes the "conceptual basis of grammatical relationships". Cognitive Grammar characterizes the subject "as a nominal whose profile corresponds to the trajectory of a profiled relationship, and an object as one whose profile corresponds to a landmark" (Langacker 2013: 210). The Chinese MDC is well-suited to this conceptual characterization or understanding of grammatical relationships.

(25) John pao jin wuzi.

John run enter house

'John entered the house by running.'

In this example, John is the trajector that is profiled and wuzi is the landmark and in its English equivalent, John is aligned with the subject and house (i.e., wuzi) with the object.

However, it is notoriously difficult to apply the grammatical relationships Subject and Object to a language like Chinese, which does not show much morphology. In a simple sentence such as John chi le yi ge pingguo, one can argue that John is the subject and yi ge pingguo is the object, based upon the linear constituency order such as SVO.

(26) John chi le yi ge pingguo.

John eat ASP one CLA apple $\quad($ CLA $=$ Classifier $)$

'John ate an apple.'

However, an example traditionally classified as a simple sentence (e.g., Chao 
1968; Li and Thompson 1981) containing a result or directional verb may not produce a perfectly clear analysis. In fact, I would argue that this construction is a complex sentence. Let us examine the resultative structure.
John kan dong
zhe ben shu le. ${ }^{7}$
John look understand this CLA book CRS
'John read the book and as a result he understood it.'

The traditional analysis is to take $s h u$ as the object of the compound verb kan dong, and thus, the sentence has an SVO structure, that is, the same analysis as the sentence John chi le yige pingguo. An alternative analysis, as argued in Fong (2015), is to take dong shu le as the complement of the verb kan. Thus, the grammatical relation that dong shu le has is that of a complement, rather than of an object as such, since it is not a regular noun phrase.

This "radical" idea is supported by the evidence that the negative scope with $b u$ 'not' falls on this complement John kan [bu dong zhe ben shu] 'John read the book, but he did not understand it'.
John kan bu dong zhe ben shu.
John look not understand this CLA book
'John read the book, but he did not understand it.'

This sentence means that John read but he did not understand, but this sentence does not mean that John did not read the book. Furthermore, if the noun phrase is a language, the dong-complement is more acceptable, as in John (kan) dong fawen que bu dong yingwen 'John (look) understand French but not understand English' (John understands French but not English). The treatment of dong zhe ben shu le as a constituent may also lie in the fact that it can be a response to an echo question. For instance, if one cannot hear (27) clearly and asks Ni shuo John kan shenme 'you say John look what', the reply can be dong zhe ben shu le. We could also make a contrast by saying that John kan dong zhe ben shu que bu dong na ben shu, which translates to 'John look understand this CLA book but not understand that CLA book' (John understands this book but does not understand that book). If one asks a similar question to the previous example about John understanding French but not English, one can reply with (John) dong fawen que bu dong yingwen. The items dong fawen and bu dong yingwen seem to be constituents because what John understands is French, not anything, and what John does not understand is English, not anything. In other words, dong in this construction is the profile determinant or head and fawen and yingwen are its complements. In (27), the entire predicate is kan dong zhe ben shu le, with kan functions as head, namely the main verb, and dong zhe ben shu le as its complement.

7 A reviewer points out that dong shu le is not so acceptable, and I concur. However, I find that if we make shu specific, the acceptability of this string will increase. I am not sure if dong shu le and dong zhe ben shu le should be analyzed differently. 
It is a general case in Chinese that the negative scope falls on the complement but not the head, for example, John da [bu si zhe zhi gou] — 'John did not kill this dog by hitting it'

(29) John da bu si zhe zhi gou.

John hit not die this CLA dog

'John did not kill the dog by hitting it.'

Again, it means that John hit the dog, but it did not die due to his hitting it. Furthermore, this "adjunct-insertion" suggests that the items dong shu and si zhe zhi gou are constituents, and they serve as complements of the (main) verb. The linear constituency order of this sentence is then NP V V NP, which is complex with shu being the complement of dong but not kan. More arguments for this analysis can be found in Fong (2015).

This analysis can be extended to that for the MDC in Chinese. In (30), the item jin wuzi functions as a complement of pao. If we negate the sentences as John pao [bu jin wuzi], the negative scope falls on the complement jin wuzi. The sentence means that John ran, but he did not enter the house, and it does not imply that John did not run.

(30) John

$$
\text { pao } \quad\left[{ }_{\text {complement }} j \text { in wuzi }\right]
$$

Thus, we regard jin wuzi as a complement of the verb pao, assuming that it is an argument of the MDC. We can keep the relations to the phrasal level, i.e., headcomplement-modifier.

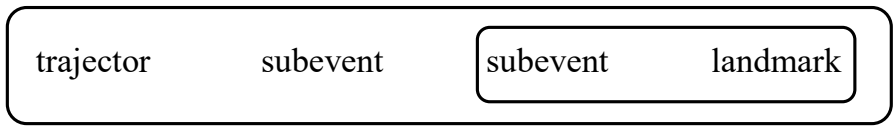

Figure 12 Conceptual basis of grammatical relationship

Thus, the MDC provides two arguments trajectory and landmark, and two subevents, as Figure 12 shows.

\section{Arguments and conceptual structure}

Either the traditional analysis or the alternative can be accommodated in the PA; as for Jackendoff (2002: 151), the grammatical function tier is "a way to regulate more precisely the expression of argument structure". We can take a resultative construction in Chinese John kan dong zhe ben shu le 'John has read and understood this book' as an example. Since the argument structure of kan is [Experiencer NP, Stimulus NP], and that of dong is also [Experiencer NP, Stimulus NP], the outcome of the overall argument structure of the sentence has one Experiencer and one Stimulus.

Under the alternative analysis, the verb kan licenses either a noun phrase or a complement clause, which echoes Jackendoff's (2002: 140) observation that "the 
verb specifies only the semantic properties of its argument and specifies nothing about the syntax of the corresponding syntactic argument".

(31) kan [zhe ben shu]

kan [dong zhe ben shu]

The PA is a fitting model for Chinese in this respect. The predicate dong can be a monovalent predicate but in (27) it can license a stimulus argument $s h u$, which is predicated of the experiencer, that is, John. The composite structure of (27) can be analyzed into its components, with two propositions:

(i) John kan zhe ben shu.

(ii) John dong zhe ben shu.

There is no overt experiencer (or "subject" in some frameworks) before dong in the composite structure *John kan John dong zhe ben shu le. The interpretation of this predication relation lies in the semantic and pragmatic knowledge of the speaker of Chinese, namely, John read the book and he understood it. Under the PA and Simpler Syntax, the understood experiencer of dong is provided by the interface rules and there is no underlying subject in the structure. This analysis also lends support to the argument against positing a level of syntactic relations, as Croft (2001) argues, while the moronic relations between the verbs and the whole Resultative Construction, that is, their syntactic roles are maintained.

As the MDC is more complicated than the Resultative Construction in that it can license up to three verbs, the MDC can provide further evidence that syntactic relations are not the necessary mechanism in Chinese. ${ }^{8}$

John pao jin wuzi lai.

John run enter house come

'John has run into the house.'

We can take pao as the main verb that licenses jin wuzi as a complement in the MDC and pao has the following argument structure:

$$
\begin{array}{ll}
\text { pao } & \text { [Theme NP, }, ~ \\
\text { pao } & {[\underline{\text { Theme NP, Path] }}}
\end{array}
$$

The verb pao is intransitive when used by itself such as John pao le 'John has run'. However, its path complement is licensed by the MDC. The conceptual structure of this sentence is as follows:

$$
\left.\left[_{\text {Event }} \text { PAST le }\left[_{\text {Event }} \text { pao }\left(\left[_{\text {Person }} \text { John }\right]\left[_{\text {EventPath }} j i n\right]\left(\left[_{\text {Place }} \text { wuzi }\right]\right)\right]\right)\right]\right]
$$

8 A reviewer points out that in Cantonese more complicated structure is found such as John haang faan gwo lai office ('John walked back to the office.'). In this case, I would assume the argument structures for all the four components, for instance, faan [Theme NP, Goal NP] and gwo [Theme NP, Goal NP]. The entire construction would have a trajector and a landmark. 
I have modified the conceptual structure representation by Jackendoff (2002: 366, 2010: 26), making it simpler and more geared to the structure of Chinese. How it differs from its English counterpart John ran into the house is that the path in Chinese can be conceptualized as an event as well. Thus, arguably, the Chinese sentence consists of two subevents, realized by the predicates pao and jin, respectively. If we examine the semantics of the second predicate more closely, we can represent it in the following terms:

$$
\left[_{\text {Event }} \mathrm{JIN} / \mathrm{GO} \quad\left(\left[_{\text {Thing }} x\right],\left[_{\text {Path }} \mathrm{RU} / \mathrm{INTO}\left(\left[_{\text {Thing }} y\right]\right)\right]\right.\right.
$$

The path is necessary here, as jin wuzi indicates that the person was in the house as his/her goal and in Chinese can be represented by $r u$ 'into' (or jin, but not jin jin). The $x$ 'thing' is the theme participant for the function of JIN/GO for motion, and the argument of goal is the argument of RU/INTO, which functions as the other argument of JIN/GO. Thus, $x$ is the theme and $y$ is the goal, and the path is realized by RU/INTO $[y]$. The verb jin has a further conceptual aspect of meaning that suggests that the end result of X's moving is his being in the house.

$$
\begin{aligned}
& \text { John jin le wuzi. } \\
& \text { John enter ASP house } \\
& \text { 'John entered the house.' }
\end{aligned}
$$

The directional verb jin, which can represent other directional verbs, produces further complexity of meaning in the conceptual structure. The argument structure of $j i n$ is bivalent.

\section{[Theme NP, Goal NP]}

Similar to other directional verbs, the verb jin can occur independently as a motion verb or a main verb (Fong 2016 argues for the First-verb-as-main-verb Hypothesis in the MDC), as in (36) or the verb can occur in the MDC as a path verb taking a place or goal as its argument. (37) contains only the verb jin, which signals movement from some place to the house. The verb, thus, has the following conceptual structure. ${ }^{9}$

$$
\begin{aligned}
& {\left[\text { Event } _ { \text { GO } } \mathrm { G } \left(\left[_{\text {Thing }} x\right],\left[_{\text {Path }} \operatorname{INTO}\left(\left[_{\text {Thing }} y\right]\right)\right]\right.\right.} \\
& {\left[_ { \text { Event } } \mathrm { JIN } \left(\left[_{\text {Thing }} J o h n\right],\left[_{\text {Path }} \operatorname{JIN}\left(\left[_{\text {Thing }} \text { wuzi }\right]\right)\right]\right.\right.}
\end{aligned}
$$

9 A reviewer concerns the relevance of the analysis here to Cantonese. My response is there is relevance. For instance, the Cantonese verb jap 'enter' licenses a complement as in John jap zo fong ('John went into the room.'), and it can be preceded by a motion verb like haang 'walk'. However, since Cantonese allows three directional verbs as in John haang faan gwo lai office ('John walked back to the office.'), the Cantonese syntax has to allow them with one more slot than that of Mandarin. Yet, I would take this case as echoing Jackendoff (2010: 314) that it serves to "modify or amplify an argument of the verbal event, namely the path". 
There are two items of jin in (39), which suggests the dual qualities of the verb. Jin is represented here as the event of going and also the path, where jin expresses an "inherent path", as "one cannot enter without going into something" (Jackendoff 2010: 314). Thus, in this case John jin le wuzi, we propose that it is the action aspect that is profiled and salient.

(40) JIN

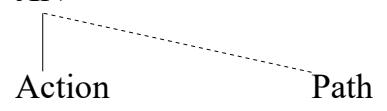

The solid line links the profiled aspect of the verb to the verb, and the dotted line connects the inherent aspect or background aspect with the verb. On the other hand, in (41) it is the Path aspect of jin that is profiled.

(41) John pao jin wuzi le.

John run enter house CRS

'John entered the house by running.'

This time, the verb and the Path aspect are connected by a solid line, while the action background aspect is linked to the verb by a dotted line.

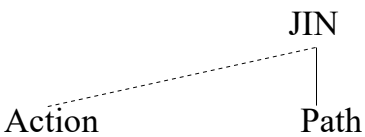

This view of the MDC is isomorphic and iconic with the Theme moving from one place to another (Goal) through the path in between. In other words, there is a natural mapping between syntax and the conceptual structure of the MDC in Chinese. This is consistent with the general principle in the PA that "meanings are decompositional" (Jackendoff 2010: 8), building on smaller conceptual units. These units are lexical items and lexical verbs in the MDC.

Following our proposal, we can generalize further to claim that all the directional verbs in Chinese contain the two aspects of meaning. Some examples follow.

(43) John pao shang shan.

John run ascend hill

'John ran up the hill.'

(44) John shang shan.

John ascend hill

'John went up the hill.'

(45) John pao guo malu.

John run cross road

'John ran across the road.' 
(46) John guo lai wo zheli.

John cross come me here

'John crossed (e.g. the road) and came to my side.'

(47) John zou chu wuzi.

John walk exit house

'John walked out the house.'

(48) John chu le wuzi.

John exit ASP house

'John went/came out of the house.'

Let us take guo for illustration. In John guo lai wo zheli 'John crossed (the road) to come to my side', guo expresses the profiled aspect of meaning as the activity of traversing, since but it does not take an NP argument. In the spirit of Jackendoff (2010: 314), guo will indicate an "inherent path" since one cannot "cross without passing from one side to the other of something". And lai wo zheli serves to "modify or amplify an argument of the verbal event, namely the path". What is interesting is that this item lai wo zheli is different from wo zheli 'my side' in that the former contains a deictic verb lai that makes the whole construction more like a verbal item than an adverbial, as Jackendoff may call this "the PP adjunct path construction". Compare the following examples.

(49) John zai wo zheli chi fan.

John at me here eat rice

'John ate rice in my place.'

(50) John lai wo zheli chi fan.

John come me here eat rice

'John came to my place to eat rice.'

The item zai wo zheli functions as an adverbial but lai wo zheli is a verbal construction like a VP or something smaller than a VP. Thus, the path in the example John guo lai wo zheli is expressed by a VP but not a PP as its English equivalent will. To make some generalizations, we should leave the category of the path unspecified.

(51) English P NP adjunct

Chinese V NP predicate

We will also have to allow this construction to function as an adjunct or a predicate. On the other hand, in John pao guo malu, pao is the motion verb and guo only profiles the salient aspect of meaning as the path of the motion event.

While the Chinese motion verb can license a verbal complement such as guo malu, which further assigns thematic roles to its arguments, Jackendoff (1990: Ch. 7, 2007: 197) has proposed one more level - the action tier in his conceptual structure model, which is modified and renamed as "macrorole tier", following Van 
Valin and LaPolla (1997). This two-tier model in the PA, for my part, captures the conceptual structures of the MDC more fully. In the macrorole tier, there are two roles, Actor and Patient. Jackendoff chiefly relies on two diagnostics to distinguish between the two macroroles.

$$
\begin{array}{ll}
\text { What } X \text { did was... } & (\mathrm{X}=\text { Actor }) \\
\text { What happened to } X \text { was... } & (\mathrm{X}=\text { Patient })
\end{array}
$$

These tests work well with examples such as the following (Jackendoff 2007: 198 $(9 \mathrm{a}, 10 \mathrm{a}))$ :

(53) The ball rolled to the wall.

What the ball did was roll to the wall. (the ball=Actor)

(54) Bill ate the apple.

What happened to the apple was that Bill ate it. (the apple = Patient)

With the example John pao jin le wuzi ('John entered the house by running'), it is quite difficult to question wuzi.
*Fasheng zai wuzi de shi shi John pao jin.
Happen at house Particle event be John run enter
'?What happened to the house was John entered it by running.'

The Chinese equivalent of the Patient diagnostic does not seem to work for wuzi, and so the Patient role cannot be aligned with the goal.

$\begin{array}{lllll}\text { (56) John pao jin } & \text { wuzi le. } \\ \text { John } & \text { run } & \text { enter } & \text { house } & \text { CRS } \\ \text { Theme } & & \text { Goal } & \\ \text { Actor } & & \text { ? }\end{array}$

Although Jackendoff (2007: 199) notices that "the direct object is the entity 'affected' by the action", he does not consider this as "a necessary property of direct object position". Yet, Jackendoff offers no solution in cases like this, and he is concerned about the status of direct object, while we recognize the post-verbal $\mathrm{NP}$ as a complement. Under the PA, jin wuzi will be assigned the path role by the construction.

Jackendoff (2007: 200-201) also proposes a different representation of conceptual structure: $X A F F Y(\mathrm{X}$ acts on/affects $\mathrm{Y})$, where $\mathrm{X}$ is Actor and $\mathrm{Y}$ Patient.

(57) John pao jin wuzi le.

$\left(\begin{array}{l}\text { JOHN GO INTO HOUSE } \\ \text { JOHN AFF }\end{array}\right)$

In (57), there is no position for Patient since John does not act on the house, and JOHN is the macrorole Actor. I assume that the Patient and Beneficiary are represented by AFF, while Jackendoff uses superscripts to distinguish them. 
The action-tier roles are also compatible with the constructional roles in Construction Grammar, which fuse with the participant roles of the verb under the Semantic Coherence Principle (Goldberg 1995: 50):

Only roles which are semantically compatible can be fused. Two roles $r_{l}$ and $r_{2}$ are semantically compatible if either $r_{1}$ can be construed as an instance of $r_{2}$, or $r_{1}$ can be construed as an instance of $r_{2}$.

In (57), the constructional roles of pao are Agent/Actor and Patient, and the participant role of the verb is Theme, namely, someone that moves. Since pao is monovalent, the Patient constructional role cannot be assigned.

$\begin{aligned} & \text { John } \\ & \text { Actor/Agent } \\ & \text { theme }\end{aligned}$
pao

The verb jin on the other hand has its participant roles as Theme and Goal, which fuse with the constructional roles Actor/Agent and Patient. The Theme role is identified as the Theme of pao through the interface rules in the PA.

\begin{tabular}{|c|c|}
\hline 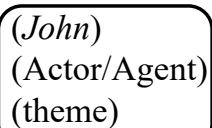 & jin \\
\hline
\end{tabular}

With (58) and (59) concatenated, the MDC is obtained.

(60) John pao jin wuzi le.

Actor Patient theme goal

If we are on the right track, the generative component of conceptual structure has a special place for the MDC in the mind/brain of Chinese speakers. Furthermore, this component of conceptual structure should presumably exist in the mind/brain of speakers of other Chinese dialects such as the speaker of Cantonese.

\section{Universal grammar and evolution}

This article proposes a different analysis of the motion-directional construction in Chinese, which is well-suited to being described in the Parallel Architecture framework, from that of a traditional one. The model sides with Jackendoff $(2002,2007,2010)$ and rejects the "syntactocentric" view of language, which is compatible with the view of language in Cognitive Grammar (e.g., Langacker 2008, Langacker 2013) and Construction Grammar (e.g., Goldberg 1995, Goldberg 2006).

As Chomsky (2015: xv-xvi) observes, Universal Grammar (UG) is often confused with linguistic universals, which are generalizations that can allow exceptions. Also, according to Chomsky, UG does not evolve and only humans do. These remarks, in my view, do not contradict to the idea of UG from some cognitive linguists such as Croft (2001: 9) that "Universal Grammar consists of 
those aspects or properties of grammatical structure which form the makeup of the grammars of all human languages". "The Universals of language are found in semantic structure and in symbolic structure, that is, mapping between linguistic function and linguistic form" (Croft 2001: 61).

"There exists a conceptual structure that represents universal aspects of human experience" (Croft 2001: 130). Conceptual structure, for Jackendoff (2010: 7 ), is also considered "to be the form (or one of the forms) in which human thought is couched - it serves as the "syntax of thought"". It is based upon this hypothesis that Jackendoff has developed his model of Conceptual Semantics. With Croft and Jackendoff's basic insights in mind, I believe that the MDC is Chinese can instantiate their hypotheses.

Metaphorically, Jackendoff $(2002,2007)$ argues that UG is a "toolkit", which is available to every grammar or language but does not need to be used by all of them. This view of UG is compatible with the "'Smorgasbord' interpretation of Universal Grammar" (Croft 2001: 10). Whatever the view, whether UG specifies a level of grammatical functions is controversial.

A level of grammatical functions, which is not obligatory in the Parallel Architecture (Jackendoff 2002: 149-151), does not figure in Chinese, although one can argue that word order may play a role in determining the subject or the object - the subject precedes the verb and the object follows it, for instance. If UG as a toolkit is available to languages such as Chinese, grammatical functions, as some tools, are not used by such languages. Thus, the Parallel Architecture, which allows syntax to be mapped onto conceptual structure, better captures the structure of Chinese.

With a similar commitment, Croft (2001) argues that syntactic relations are not necessary entities for linguistic constructions. What is needed is the meronomic relation between the construction and its components. Further, the link between the syntactic structure and semantic structure is through symbolic relations.

The syntagmatic relations among the items in the MDC in Chinese is through Merge (Boeckx 2006) or combinatoriality - "[m]eanings are decompositional" (Jackendoff 2010: 8). This interpretation of constructions built from smaller units and treating certain constructions as lexical items such as the MDC seem to have the evolutionary origin. Bickerton (2013: 461) believes that "this process [merge] must have existed before language, not as a specialized operation for a particular non-linguistic function, but as part and parcel of the brain's normal machinery for merging its own outputs". I am inclined to think that with the flexibility of the lexical items in the MDC in Chinese, the construction must have been "assembled from the meaning of its individual parts: distinct combinations produce distinct meanings" (Tallerman 2013: 452). This can be witnessed by the following examples: 
(61)

\begin{tabular}{lllll|} 
John & pao. & & & \\
John & jin & wuzi. & & \\
John & jin & qu & wuzi. & \\
John & pao & jin & $q u$ & wuzi. \\
John & pao & jin & wuzi & qu.
\end{tabular}

These examples are progressively complex, with the MDC as a result. "When one word is used in combination with other words yielding a set meaning, a construction is born" (Bybee 2013: 536).

Nevertheless, the MDC in Chinese is flexible enough to accommodate conceptual variations, which seem to bear some similarities with creole languages. In Guyanese, we find the motion-directional construction such as the following (Bickerton 2008: 64):

(62) Me walk go a house go nyam.

The Chinese MDC equivalent is:

(63) Wo zou qu wuzi qu nyam.

A further example of similarity involves the use of Serial Verb Constructions.

(64) Me carry book come get you.

(65) Wo na shu lai zhao $n i^{10}$ me carry book come get you

'I came to get you with a book.'

Chinese can further combine the MDC and Serial Verb Construction:

(66) $\mathrm{Ni}$ pa shang lai jiao John You climb up come call John

'You climbed up to call John.'

Examples (65-66) complicate the picture further. The Serial Verb Construction with the orientation verb lai 'come' appears to indicate the purpose of the main action, that is, constituting a Purpose Clause, which is a common source of the infinitival complement in the process of grammaticalization (Croft 2001: 352). In Chinese, there is of course no infinitival marker such as to in English. Quoting Stassen (1985: 73), Croft (2001: 352, example 77 repeated here as (67)) states that the Serial Verb Construction in Mandarin Chinese can be ambiguous (without the orientation verb).

(67) Ta hui jia kan qinqi.

he return home see parents [relatives]

'He returned home and saw his parents/to see his parents.'

10 A reviewer suggests that this use of lai is a relational marker specifying the goal or even "purpose". I agree that it can be analyzed as such. However, I would like to regard it as the directional verb as in (65) and (66) it has the meaning of orientation. 
With this in mind, I analyze the lai 'come' in (65) and (66) as an orientation verb rather than a Purpose Clause marker, partly because the verb still retains some "orientation" meaning component. Compare (66) with (68).

(68) $\mathrm{Ni}$ pa shang qu jiao John.
you climb up go call John
'You climbed up to call John.'

With the two orientation verbs, the speaker can show his/her relation to John, that is, closer to him or away from him.

Given the assumption that a creole is in an earlier stage of language evolution, it may not be too farfetched to assume that the MDC in Chinese has been evolving to accommodate communicative needs of the speakers. If Guyanese and Chinese allow such conceptual concatenation of lexical items and flexibility in their constructions, UG must be rich and flexible enough and the view of it as a "toolkit" appears to be a viable alternative. The "toolkit" approach to UG, from my perspective, is comparable to Bickerton's (2013) proposal of "protolanguage" - a form of language that occurred before the arrival of modern human language. The form of it depends upon one's theory, but certainly, it comprises the manipulation of symbols and "[m]eaning therefore would be the first generative component of language to emerge in the course of evolution" (Jackendoff 2007: 74). Moreover, I concur with Croft (2001: 180) that "the general rules of semantic composition correspond to the symbolic relations linking form and meaning in the most schematic or general constructions in the language." Based upon the evidence of the MDC in Chinese, I can speculate that the language structure of Chinese has remained pretty much the same since we started using the language, but only further evidence and research can ascertain this.

\section{Conclusion}

This article has argued for a constructional-cognitive account of the MotionDirectional Construction in Chinese, particularly couched within the Parallel Architecture. We first propose a conceptual definition of subordination and then argue that the MDC consists of subordination. Particularly, we propose that, alongside Langacker (2014), each verb in the MDC activates a mental space. The MDC, then, is examined in the PA framework and we suggest some merits of this approach. The PA is argued to be a viable framework in which the MDC in Chinese can be studied fruitfully. In the PA, a grammatical function tier is proposed, and we argue that perhaps this level should not be universal and is not a necessary construct as the Chinese data show. Syntactically, the directional verbs in Chinese can occur as main verbs indicating motion and inherent path. Conceptually, different aspects of meaning of the verb can be activated through their position in the construction. They can be expressed in the PA with a level of conceptual structure. Furthermore, we examined the MDC in evolutionary terms suggesting that the MDC Chinese is diachronically evolving. Finally, the research 
reported here will also be expected to open a new path for the study of Chinese (including different varieties) in general, and the study of MDC in particular.

\section{Acknowledgments}

I thank Ray Jackendoff and the reviewers for their valuable comments.

\section{References}

Bickerton, Derek. 2008. Bastard tongues: A trailblazing linguist finds clues to our common humanity in the world's lowliest languages. New York: Hill and Wang.

Bickerton, Derek. 2013. The origins of syntactic language. In Maggie Tallerman, and Kathleen Gibson (eds.), The Oxford handbook of language evolution, 456-468. Oxford: Oxford University Press.

Boas, Hans C. 2003. A constructional approach to resultatives. Stanford, CA: CSLI Publications.

Boeckx, Cedric. 2006. Linguistic minimalism: Origins, concepts, methods, and aims. Oxford: Oxford University Press.

Bybee, Joan. 2013. Domain-general processes as the basis for grammar. In Maggie Tallerman, and Kathleen Gibson (eds.), The Oxford handbook of language evolution, 528-536. Oxford: Oxford University Press.

Chao, Yuen Ren. 1968. The grammar of spoken Chinese. Berkeley, CA: University of California Press.

Cheung, Hung Nin Samuel. 2007. Xianggang Yueyu yufa de yanjiu [A grammar of Cantonese as spoken in Hong Kong]. The Chinese University Press.

Chomsky, Noam. 2015. Exploring the boundaries of Babel. In Andrea Moro, The boundaries of Babel, xi-xiii. Cambridge, MA: MIT Press.

Cristofaro, Sonia. 2003. Subordination. Oxford: Oxford University Press.

Cristofaro, Sonia. 2014. Is there really a syntactic category of subordination? In Laura Visapää, Jyrki Kalliokoski, and Helena Sorva (eds.), Context of subordination: Cognitive, typological and discourse perspectives, 73-91. Amsterdam: John Benjamins.

Croft, William. 2001. Radical construction grammar: Syntactic theory in typological perspective. Oxford: Oxford University Press.

Croft, William. 2012. Verbs: Aspect and causal structure. Oxford: Oxford University Press.

Culicover, Peter W. 2013. Explaining syntax: Representations, structure, and computation. Oxford: Oxford University Press.

Culicover, Peter W. 2015. Simpler syntax and the mind: Reflections on syntactic theory and cognitive science. In Ida Toivonen, Piroska Csúri, and Emile van der Zee (eds.), Structures in the mind: Essays on language, music, and cognition in honor of Ray Jackendoff, 3-20. Cambridge, MA: MIT Press.

Culicover, Peter W., and Ray Jackendoff. 2005. Simpler syntax. Oxford: Oxford University Press.

Farrell, Patrick. 2005. Grammatical relations. Oxford: Oxford University Press. 
Fauconnier, Gilles. 1997. Mappings in thought and language. Cambridge: Cambridge University Press.

Fauconnier, Gilles. 2007. Mental spaces. In Dirk Geeraerts, and Hubert Cuyckens (eds.), The Oxford handbook of Cognitive Linguistics, 351-376. Oxford: Oxford University Press.

Fauconnier, Gilles, and Mark Turner. 2002. The way we think: Conceptual blending and the mind's hidden complexities. New York: Basic Books.

Fong, Ronald. 2015. A constructional-cognitive analysis of Chinese directionals. Cognitive Semantics 1(1). 104-130.

Fong, Ronald. 2016. Chinese as satellite-framed: A constructional-cognitive interpretation. Cognitive Linguistic Studies 3(2). 233-258.

Geuder, Wilhelm, and Matthias Weisgerer. 2008. Manner of movement and the conceptualization of force, slides, Journée d'étude 'Il y a manière et manière', Université d'Artois, Arras, France.

Goldberg, Adele E. 1995. Constructions: A construction grammar approach to argument structure. Chicago: Chicago University Press.

Goldberg, Adele E. 2006. Constructions at work: The nature of generalization in language. Oxford: Oxford University Press.

Huang, C-T James, Y-H Audrey Li, and Yafei Li. 2009. The syntax of Chinese. Cambridge: Cambridge University Press.

Huddleston, Rodney, and Geoffrey Pullum. 2002. The Cambridge grammar of the English language. Cambridge: Cambridge University Press.

Jackendoff, Ray. 1990. Semantic structures. Cambridge, MA: MIT Press.

Jackendoff, Ray. 2002. Foundations of language: Brain, meaning, grammar, evolution. Oxford: Oxford University Press.

Jackendoff, Ray. 2007. Language, consciousness, culture: Essays on mental structure. Cambridge, MA: MIT Press.

Jackendoff, Ray. 2010. Meaning and the lexicon: The parallel architecture 1975-2010. Oxford: Oxford University Press.

LaPolla, Randy J. 1992. Arguments against 'subject' and 'direct object' as viable concepts in Chinese. Bulletin of the Institute of History and Philology Academia Sinica 63(4). 759-813.

Langacker, Ronald W. 1991. Foundations of cognitive grammar II: Descriptive application. Stanford: Stanford University Press.

Langacker, Ronald W. 2008. Cognitive grammar: A basic introduction. Oxford: Oxford University Press.

Langacker, Ronald W. 2013. Essentials of Cognitive Grammar. Oxford: Oxford University Press.

Langacker, Ronald W. 2014. Subordination in a dynamic account of grammar. In Laura Visapää, Jyrki Kalliokoski, and Helena Sorva (eds.), Context of subordination, 17-72. Amsterdam: John Benjamins.

Levin, Beth and Malka Rappaport Hovav. 2013. Lexicalized meaning and manner/ result complementarity. In Boban Arsenijević, Berit Gehrke, and Rafael Marín (eds.), Studies in the composition and decomposition of event predicates. New 
York: Springer.

Levinson, Stephen C. 2003. Space in language and cognition: Explorations in cognitive diversity. Cambridge: Cambridge University Press.

Li, Charles, and Sandra Thompson. 1981. Mandarin Chinese: A functional reference grammar. Berkeley: University of California Press.

Loar, Jian Kang. 2011. Chinese syntactic grammar: Functional and conceptual principles. New York: Peter Lang.

Slobin, Dan. 2004. The many ways to search for a frog: Linguistic typology and the expression of motion events. In Sven Strömqvist, and Ludo Verhoeven (eds.), Relating events in narrative volume 2: Typological and contextual perspectives, 219-257. Mahwah, NJ: LEA.

Stassen, Leon. 1985. Comparison and universal grammar. Oxford: Basil Blackwell.

Tallerman, Maggie. 2013. What is syntax? In Maggie Tallerman, and Kathleen Gibson (eds.), The Oxford handbook of language evolution, 442-455. Oxford: Oxford University Press.

Talmy, Leonard. 2016. Properties of main verbs. Cognitive Semantics 2(2). 133-163.

Traugott, Elizabeth Closs, and Graeme Trousdale. 2013. Cosntructionalization and constructional changes. Oxford: Oxford University Press.

Van Valin, Robert D Jr, and Randy J LaPolla. 1997. Syntax: Structure, meaning and function. Cambridge: Cambridge University Press.

Yiu, Yuk Man Carine. 2005. Spatial extension: Directional verbs in Cantonese. Hong Kong: The Hong Kong University of Science and Technology dissertation.

Yiu, Yuk-man Carine. 2013. Directional verbs in Cantonese: A typological and historical study. Language and Linguistics 14(3). 511-569.

Mailing address: Department of English, Faculty of Arts and Humanities, University of Macau, Avenida da Universidade, Taipa, Macau

Email: $\quad$ ronaldf@umac.mo

Received: January 26, 2017

Accepted: $\quad$ December 15, 2017 


\title{
漢語移動 - 方向構式一一概念及認知分析
}

\author{
馮潤華 \\ 澳門大學
}

\section{提要}

本文利用 Jackendoff 的概念語意學及 Langacker 的認知語法學理論來分析漢語的移 動 - 方向構式。本文首先論證移動 - 方向構式具有概念上的附屬性來表示心理空 間, 然後進一步考察這構式的句法及語意行爲來說明其爲一種構式習語。本文又以 “爬” 爲例, 廣義地認爲行動動詞典型地表示移動的不同方式。在概念語意學的框 架下, 本文認爲語法關係並不是必須的, 反而我們需要的是在概念結構上的論元及 概念結構。本文最後提供語料指出移動 - 方向構式跟語言類型學的關係。

\section{關鍵詞}

附屬性, 方向, 平衡架構, 構式, 概念結構 